\title{
Calcium Calmodulin-Stimulated Adenylyl Cyclases Contribute to Activation of Extracellular Signal-Regulated Kinase in Spinal Dorsal Horn Neurons in Adult Rats and Mice
}

\author{
Feng Wei, ${ }^{1}$ Kunjumon I. Vadakkan, ${ }^{2}$ Hiroki Toyoda, ${ }^{2}$ Long-Jun Wu,,${ }^{2}$ Ming-Gao Zhao, ${ }^{2}$ Hui Xu, ${ }^{2}$ Fanny W.F. Shum, ${ }^{2}$ \\ Yong Heng Jia, ${ }^{2}$ and Min $\mathrm{Zhuo}^{2}$ \\ ${ }^{1}$ Department of Biomedical Sciences, University of Maryland Dental School, Baltimore, Maryland 21201 and ${ }^{2}$ Department of Physiology, Faculty of \\ Medicine, University of Toronto, University of Toronto Centre for the Study of Pain, Toronto, Ontario, Canada M5S 1A8
}

\begin{abstract}
The extracellular signal-regulated kinase (Erk) cascades are suggested to contribute to excitatory synaptic plasticity in the CNS, including the spinal cord dorsal horn. However, many of their upstream signaling pathways remain to be investigated. Here, we demonstrate that glutamate and substance P (SP), two principal mediators of sensory information between primary afferent fibers and the spinal cord, activate Erk in dorsal horn neurons of both adult rat and mouse spinal cord. In genetic knock-out mice of calcium calmodulin-stimulated adenylyl cyclase subtypes $1(A C 1)$ and $8(A C 8)$, activation of Erk in dorsal horn neurons were significantly reduced or blocked, either after peripheral tissue inflammation or by glutamate or SP in spinal cord slices. Our studies suggest that AC1 and AC8 act upstream from Erk activation in spinal dorsal horn neurons and the calcium-AC1/AC8-dependent Erk signaling pathways may contribute to spinal sensitization, an underlying mechanism for the development of persistent pain after injury.
\end{abstract}

Key words: adenylyl cyclases; Erk; spinal dorsal horn; mice; spinal cord; glutamate; substance P; cyclic Amp; Camp; C-Amp

\section{Introduction}

Glutamate is the major excitatory neurotransmitter in the CNS, and glutamatergic synapses undergo activity-dependent alterations (Bliss and Collingridge, 1993; Nicoll and Malenka, 1995; Stevens, 1998). Activity-dependent long-term potentiation (LTP) in the hippocampus, which depends on gene expression, is thought to play a role in the consolidation of memory (Frey et al., 1993; Kandel, 1997). Cumulative evidence suggests that longterm plasticity of glutamatergic synapses in the spinal dorsal horn may contribute to persistent pain caused by tissue or nerve injury (Woolf and Thompson, 1991; Coderre et al., 1993) (for review, see Dubner and Basbaum, 1994; Zhuo, 2004). Glutamate is the fast neurotransmitter conveying peripheral nociceptive input to the spinal cord, whereas substance P (SP) may act as a peptide transmitter (Yoshimura and Jessell, 1990; Li et al., 1998; Ikeda et al., 2003). Brief tetanic stimulation of primary afferent fibers in-

\footnotetext{
Received March 18, 2005; revised Nov. 8, 2005; accepted Nov. 14, 2005.

This work was supported by grants from the EJLB-Canadian Institutes of Health Research (CIHR) Michael Smith Chair in Neurosciences and Mental Health in Canada, the Canada Research Chair, the Neuroscience Canada Brain Repair Program, and CIHR, and National Institutes of Health National Institute of Neurological Disorders and Stroke Grant 42733.

Correspondence should be addressed to either of the following: Dr. Min Zhuo, Department of Physiology, University of Toronto Faculty of Medicine, Medical Sciences Building, Room \#3342, 1 King's College Circle, Toronto, Ontario, Canada M5S 1A8, E-mail: min.zhuo@utoronto.ca; or Dr. Feng Wei, Department of Biomedical Sciences, University of Maryland Dental School, 666 West Baltimore Street, Baltimore, MD 21201, E-mail: fwei@umaryland.edu.

DOI:10.1523/JNEUROSCI.3292-05.2006

Copyright $\odot 2006$ Society for Neuroscience $\quad$ 0270-6474/06/260851-11\$15.00/0
}

duced LTP of synaptic transmission at dorsal horn synapses (Randic et al., 1993; Sandkuhler and Liu, 1998). NMDA receptor antagonists in the spinal cord blocked synaptic potentiation and significantly attenuated behavioral hyperalgesia in animals and chronic pain in humans (for review, see Dubner and Basbaum, 1994; Zhuo, 2004). More interestingly, inhibitors of new protein synthesis applied locally to the spinal cord attenuated behavioral nociceptive responses to formalin injection (Kim et al., 1998). Therefore, it is hypothesized that activation of NMDA or other receptors leads to gene transcription and synthesis of new proteins in dorsal horn neurons during the development of persistent/chronic pain. An important task is to identify the signaling pathways coupling NMDA receptor activation to changes in gene expression.

Extracellular signal-regulated kinase (Erk), one of major subfamilies of mitogen-activated protein kinases (MAPKs), is a serine/threonine kinase critical for the transduction of signals from cell surface receptors to the nucleus (Robinson and Cobb, 1997; Impey et al., 1998; Orban et al., 1999) through the translocation of its phosphorylated form (Kornhauser and Greenberg, 1997). Activation of NMDA receptors induce phosphorylation of Erk in hippocampal neurons (Gille et al., 1992; Kurino et al., 1995; Xia et al., 1996), possibly through protein kinase A (PKA) and protein kinase C (PKC) (Huang et al., 1994; Impey et al., 1998; Roberson et al., 1999; Wong et al., 1999). Such Erk phophorylation has also been reported in the spinal cord (Ji et al., 1999; Karim et al., 2001; Hu and Gereau, 2003; Hu et al., 2003; Lever et al., 2003; Adwanikar et al., 2004; Kawasaki et al., 2004). 
Adenylyl cyclase 1 (AC1) and cyclase 8 (AC8) are the two major calmodulin (CaM)-stimulated ACs in the CNS. They couple NMDA receptor-induced cytosolic $\mathrm{Ca}^{2+}$ elevation to cAMP signaling pathways (Chetkovich and Sweatt, 1993; Wong et al., 1999). Recent reports showed that spinal Erk was activated after tissue injury in adult rats (Ji et al., 1999; Ji et al., 2002). However, less is known whether AC1 and AC8 signal pathways are upstream of Erk activation in spinal sensory neurons. Here, we used $A C 1$ knock-out, $A C 8$ knock-out, and $A C 1 \& 8$ double knock-out (DKO) mice to test the roles of adenylyl cyclases in chemical- and injury-induced Erk activation.

\section{Materials and Methods}

Animals. Experiments were performed on adult male Sprague Dawley rats (250-300 g; Harlan, Indianapolis, IN) and C57BL/6 mice (20-35 g; The Jackson Laboratory Bar Harbor, ME). Mutant male mice lacking $A C 1, A C 8$, or $A C 1 \& 8$, and wild-type (WT) mice were of mixed $129 \times$ Black Swiss background (Wong et al., 1999; Schaefer et al., 2000; Wei et al., 2002). We generated WT/WT, $A C 1$ knock-out (KO)/AC8 WT, AC8 $\mathrm{KO} / A C 1 \mathrm{WT}$, and $A C 1 \mathrm{KO} / A C 8 \mathrm{KO}$ breeders from $A C 1$ heterozygous/ $A C 8$ heterozygous matings, and used the offspring from these breeders for the described studies. To minimize drift of background in a given genotype line, we used several breeding pairs. Both WT and mutant mice were well groomed and showed no signs of abnormality or any obvious motor defects. No indication of tremor, seizure, or ataxia was observed. Wild-types and knock-outs were not physically distinguishable from each other. Experimenters were blind to the genotypes. Our previous studies (Wei et al., 2002) showed that behavioral changes to acute noxious stimuli as well as early behavioral responses to inflammatory agents like formalin were not affected in these mutant mice. In addition, injection of forskolin into the forebrain can rescue behavioral allodynia in $A C 1 \& 8$ DKO mice, suggesting that the changes in behavioral responses are unlikely caused by structural defects. The Animal Care and Use Committee of University of Maryland Dental School and University of Toronto approved all protocols. The animals were kept under a $12 \mathrm{~h}$ light/ dark cycle with food and water ad libitum, and habituated to the laboratory room at least $1 \mathrm{~h}$ before the start of experiments.

In vitro spinal cord slices. Rats and mice were anesthetized with $2 \%$ halothane and rapidly perfused through the ascending aorta with oxygenated, cold artificial cerebrospinal fluid [ACSF; containing the following (in mM): $124 \mathrm{NaCl}, 4 \mathrm{KCl}, 26 \mathrm{NaHCO}_{3}, 2.0 \mathrm{CaCl}_{2}, 1.0 \mathrm{MgSO}_{4}, 1.0$ $\mathrm{NaH}_{2} \mathrm{PO}_{4}, 10$ D-glucose, $\mathrm{pH}$ 7.4] and the lumbar spinal cords were quickly removed. Transverse spinal cord slices ( $500 \mu \mathrm{m}$ thick) were cut at $4^{\circ} \mathrm{C}$ using a Vibratome, and the sections were perfused at $5 \mathrm{ml} / \mathrm{min}$ with oxygenated ACSF. The slices were slowly brought to final temperature of $30^{\circ} \mathrm{C}$. The slices were treated with different drugs: L-glutamate $(0.1-100$ $\mu \mathrm{M}$; Sigma), SP (10 $\mu \mathrm{M}$; RBI, Natick, MA), capsaicin (1 $\mu \mathrm{M}$; Sigma), or forskolin $(10 \mu \mathrm{M}$; RBI) for $30 \mathrm{~min}$. Neurokinin 1 (NK1) antagonist L-733060 (RBI) was used to block the effect of SP. To investigate the role of NMDA, AMPA/kainate, or metabotropic glutamate receptors on glutamate-induced phenomena, we added 2-amino-5-phosphonopentanoic acid (AP-5; $50 \mu \mathrm{M}$; Sigma), 6-cyano-7-nitroquinoxaline-2,3dione (CNQX; $20 \mu \mathrm{M}$; RBI), $\alpha$-methyl-4-carboxyphenylglycine (MCPG; $500 \mu \mathrm{M} ; \mathrm{RBI}$ ), or trans-1-amino-1,3-cyclopentanedicarboxylic acid (tACPD; $200 \mu \mathrm{M}$; RBI) to ACSF for 10 min before and during glutamate application. Untreated slices served as controls. Subsequently, slices were fixed with $4 \%$ paraformaldehyde in $0.1 \mathrm{M}$ phosphate buffer (PB) for $24 \mathrm{~h}$ and cryoprotected in $30 \%$ sucrose in $0.1 \mathrm{~m}$ PBS. Transverse sections (30 $\mu \mathrm{m})$ were cut on a cryostat at $-20^{\circ} \mathrm{C}$ and were immersed in PBS until immunostaining was performed.

In vivo animal studies. To investigate whether phosphorylation of Erk is implicated in the spinal nociceptive activity generated by peripheral tissue injury, several pain models in both rat and mouse were used. Groups of three to six animals received one of the following unilateral noxious stimuli: (1) acute thermal stimulation of the ventral part of one hindpaw by placing the animal on $55^{\circ} \mathrm{C}$ hot plate for $12 \mathrm{~s}$, which is the average hindpaw withdrawal latency to heat in the rat, with temporal halothane anesthesia, or (2) ongoing chemical stimulation by subcuta- neous injection of formalin ( $5 \%$ in saline; Sigma) or capsaicin ( $100 \mu \mathrm{g} / 50$ $\mu \mathrm{l}$ in rat and $10 \mu \mathrm{g} / 10 \mu \mathrm{l}$ in mouse, prepared in 5\% Tween 80 in saline; Sigma) into the plantar surface of unilateral hindpaw in awake animals. Each experimental group for chemical and inflammatory stimulation has an associated control group receiving a vehicle injection. Additionally, to examine whether or not innocuous tactile stimulation influences activation of spinal Erk, the plantar surface of one hindpaw was gently brushed repeatedly with a paint brush (\#4; Winsor \& Newton, Middlesex, UK) for $12 \mathrm{~s}$.

At the appropriate time point after unilateral peripheral stimulation, animals were deeply anesthetized with halothane and perfused through the ascending aorta with warm saline, followed by cold $0.1 \mathrm{M}$ phosphate buffer containing $4 \%$ paraformaldehyde. The lumbar spinal cord was removed, postfixed in fresh fixative at least for $4 \mathrm{~h}$, and cryoprotected by placing it in $30 \%$ sucrose in $0.1 \mathrm{~m}$ PBS for $48 \mathrm{~h}$. The ventral horn contralateral to the stimulation was marked by a small cut so that the ipsilateral side of spinal cord could be identified after sectioning. Transverse sections $(30 \mu \mathrm{m})$ were cut with a cryostat and processed for immunostaining.

Pharmacological and behavioral experiments. Experiments were performed as described previously (Wei et al., 2002). Mice were anesthetized with $3 \%$ isoflurane with $30 \% \mathrm{O}_{2}$ balanced with nitrogen. The lumbar vertebrae were slightly flexed, spines were palpated and the needle was advanced manually through the interspinal space lateral to the spinous process as described previously (Hylden and Wilcox, 1980). A total of 0.5 $\mu \mathrm{l}$ of forskolin (12 nmol) or vehicle (20\% DMSO in filter-sterilized PBS, $\mathrm{pH}$ 7.4) was infused at a rate of $0.05 \mu \mathrm{l} / \mathrm{min}$. The needle was withdrawn 5 min after the completion of the injection. After $30 \mathrm{~min}, 10 \mu \mathrm{l}$ of $50 \%$ Complete Freund's adjuvant (CFA; Sigma) in normal saline was subcutaneously injected into the dorsal side of the left hindpaw.

Mechanical allodynia was tested using von Frey filament no. 2.44 (0.4 $\mathrm{mN}$ ) (Stoeling, Wood Dale, IL), which was found to be innocuous in AC1\&8 DKO mice (Wei et al., 2002), by pressuring over the dorsum of the ipsilateral hindpaw to the point of bending before and after hindpaw injection of CFA. Measurements were taken at an interval of $5 \mathrm{~min}$ for five times. Percentage response of the hindpaw withdrawal was calculated as the number of positive responses divided by 5 (number of von Frey filament application) times 100 .

Immunohistochemistry. Immunostaining was performed using freefloating sections (Wei et al., 1999). Briefly, the spinal cord sections were first treated with $0.75 \%$ Triton $\mathrm{X}-100$ and $1 \% \mathrm{H}_{2} \mathrm{O}_{2}$ in PBS for $1 \mathrm{~h}$, and then processed for $30 \mathrm{~min}$ in $3 \%$ normal goat serum (NGS), followed by incubation with anti-phospho-p44/42 Erk (Thr202/Tyr204) monoclonal antibody (diluted 1:500; Cell Signaling, Beverly, MA) overnight at room temperature. Secondary reactions with biotinylated goat anti-mouse immunoglobulin (1:400; Vector Laboratories, Burlingame, CA) for $1 \mathrm{~h}$ were followed by avidin-biotin-peroxidase complexes (1:100; Vector Laboratories) for $1 \mathrm{~h}$. A nickel-intensified diaminobenzidine with glucose oxidase was used as the final chromogen. Sections were washed several times, mounted on gelatinized slides, dehydrated through a series of ethanol solutions, cleared in xylene, and covered with glass coverslips. Controls, performed by replacing primary antibody with $1 \%$ NGS in the protocol, exhibited no staining.

To further confirm the activation of Erk in dorsal horn neurons, we double-labeled spinal cord sections from WT mice that were given a unilateral hindpaw injection of formalin (taken $15 \mathrm{~min}$ after the injection). Sections were incubated with mouse anti-phospho-p44/42 Erk antibody (1:500) and rabbit anti-NeuN antiserum (diluted 1:300; Chemicon, Temecula, CA) overnight. These phosphorylated Erk (pErk) and neuronal markers were visualized using the species-appropriate Alexa Flour 488- and 568-conjugated secondary antibodies (diluted 1:600; Invitrogen), respectively. Sections were mounted on gelatin-coated slides and coverslipped with Vectashield (Vector Laboratories).

Western blot analysis. The dorsal half of the lumbar spinal cord from WT, $A C 1 \mathrm{KO}, A C 8 \mathrm{KO}$, and $A C 1 \& 8 \mathrm{DKO}$ were carefully dissected out and homogenized. Equal amounts of the protein were then electrotransferred onto polyvinylidene fluoride membrane (Invitrogen, San Diego, CA) and were probed with anti-MAPK/Erk1/2 polyclonal antibody (Cell Signaling, Beverly, MA) with anti- $\beta$-tubulin (Sigma, St. Louis, MO) as a 
loading control. The membranes were incubated with horseradish peroxidase-conjugated secondary antibody (anti-rabbit IgG), and 42 and $44 \mathrm{kDa}$ bands were visualized using an ECL system (PerkinElmer, Wellesley, MA). Results were expressed as means \pm SEM and statistical comparisons were performed using the $t$ test.

Whole-cell patch-clamp recordings in spinal cord slices. Whole-cell recordings were made from spinal slices of C57BL/6 mice at postnatal days $17-19$, as described previously ( $\mathrm{Li}$ and Zhuo, 1998). Slices were incubated in a submerged recovery chamber with oxygenated $\left(95 \% \mathrm{O}_{2}\right.$ and $5 \% \mathrm{CO}_{2}$ ) ACSF containing the following (in $\mathrm{mM}$ ): $95 \mathrm{NaCl}, 1.8 \mathrm{KCl}, 0.5$ $\mathrm{CaCl}_{2}, 7 \mathrm{MgSO}_{4}, 26 \mathrm{NaHCO}_{3}, 1.2 \mathrm{KH}_{2} \mathrm{PO}_{4}, 15$ glucose, and 50 sucrose for at least $1 \mathrm{~h}$ (Ruscheweyh and Sandkuhler, 2002). A single slice was then transferred to a recording chamber on the stage of a BX51W1 microscope (Olympus, Tokyo, Japan) with infrared differential interference contrast optics for visualization of whole-cell patch-clamp recording, and perfused with oxygenated recording solution at 3-4 $\mathrm{ml} / \mathrm{min}$ at room temperature. The recording solution contained the following (in $\mathrm{mM}$ ): $127 \mathrm{NaCl}, 1.8 \mathrm{KCl}, 2.4 \mathrm{CaCl}_{2}, 1.3 \mathrm{MgSO}_{4}, 26 \mathrm{NaHCO}_{3}, 1.2 \mathrm{KH}_{2} \mathrm{PO}_{4}$ and 15 glucose. Stimulations were delivered by a bipolar tungsten stimulating electrode placed at the dorsal root entry zone. EPSCs were induced by repetitive stimulations at $0.05 \mathrm{~Hz}$, and neurons were voltage clamped at $-70 \mathrm{mV}$. EPSCs were recorded from the superficial dorsal horn of the spinal cord with an Axon 200B amplifier (Molecular Devices, Union City, CA). The recording pipettes (3-5 M $\Omega$ ) were filled with solution containing the following (in mM): $145 \mathrm{~K}$-gluconate, $5 \mathrm{NaCl}, 1 \mathrm{MgCl}_{2}, 0.2$ EGTA, 10 HEPES, $2 \mathrm{Mg}$-ATP, and $0.1 \mathrm{Na}_{3}$-GTP, adjusted to $\mathrm{pH} 7.2$ with $\mathrm{KOH}, 280-300 \mathrm{mOsm}$. Bicuculline $(10 \mu \mathrm{M})$ and strychnine $(1 \mu \mathrm{M})$ were added the perfusion solution to block the inhibitory synaptic currents. LTP was induced by 80 pulses at $2 \mathrm{~Hz}$ with postsynaptic depolarization at $+30 \mathrm{mV}$ (Zhao et al., 2005). Access resistance was 15-30 M $\Omega$ and monitored throughout the experiment. Data were discarded if access resistance changed $>15 \%$ during an experiment. Signals were filtered at 1 $\mathrm{kHz}$, digitized at $10 \mathrm{kHz}$.

Data analysis. For Western blot analysis, statistical comparisons were performed using the $t$ test. For counting of labeled neurons, positive staining was studied in the L4-L5 spinal segments in both the rat and mouse. Tissue sections were first examined using dark-field microscopy to determine the gray matter laminas and landmarks according to Molander et al. (1984). The labeled neurons within the superficial dorsal horn were then examined and manually counted in 10 sections per animal under light-field microscopy. Results were expressed as mean \pm SEM. Statistical one-way ANOVA was done to compare the number of labeled cells between different groups of animals. The post hoc Scheffe $F$ test was used to identify significant differences. The investigator responsible for plotting and counting the labeled cells was blind to the experimental situation of each animal. The value $p<0.05$ was considered statistically significant. Electrophysiological results were expressed as mean \pm SEM. Statistical comparisons were performed using group $t$ test.

\section{Results}

Many studies have shown that phosphorylation of Erk correlates with Erk activation and is used routinely as an indicator of Erk activation (English and Sweatt, 1996; Obrietan et al., 1998; Ji et al., 1999; Roberson et al., 1999). In the present studies, Erk activation was evaluated by immunostaining spinal cord sections of both rat and mouse for pErk. First, we examined whether the expression levels of Erk is changed in $A C 1, A C 8$, and $A C 1 \& 8$ DKO mice compared with the WT. Second, we investigated Erk phosphorylation after either glutamate or SP receptor activation and activation of primary afferent fibers by bath application of capsaicin using spinal cord slices in vitro, a preparation better suited for pharmacological manipulation than whole-animal experiments. Third, to establish whether similar phenomena occur in vivo, we performed experiments using different pain models on persistent inflammatory pain in which obvious plastic changes of pErk expression were observed. Considering the fact that most of the previous studies were performed in rats, experiments here

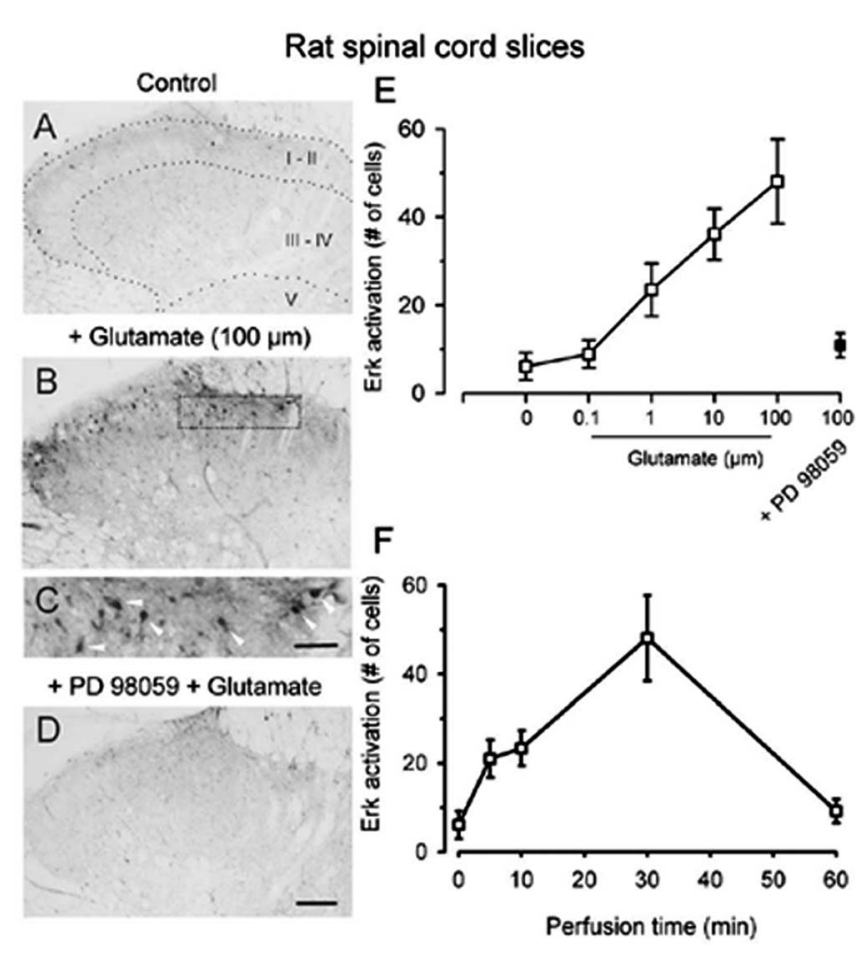

Figure 1. Dose- and time-dependent activation of Erk by glutamate in adult rat spinal cord slices. Bath application of high-dose glutamate (100 $\mu \mathrm{m}$ for $30 \mathrm{~min}$ ) induced increases in pErk immunoreactivity in dorsal horn neurons ( $\boldsymbol{B})$, especially in the superficial layer ( $\boldsymbol{C}$, arrowheads), compared with sham treatment $(\boldsymbol{A})$. This activation was completely inhibited by pretreatment with the MEK inhibitor PD98059 (D). E, Pooled data demonstrate a dose-dependent activation of Erk by bath application of glutamate ( $30 \mathrm{~min}$; open squares). Erk activation was blocked by the MEK inhibitor PD98059 (filled squares). $\boldsymbol{F}$, Erk activation depended on the perfusion time of glutamate (100 $\mu \mathrm{m} ; 5,10,30$, and $60 \mathrm{~min}$ ). Scale bars: (in D) $\boldsymbol{A}, \boldsymbol{B}, \boldsymbol{D}, 100 \mu \mathrm{m}$; (in C) C, $40 \mu \mathrm{m}$. Error bars indicate SEM.

were performed in both rats and mice to determine possible differences between species.

\section{Activation of Erk by glutamate and SP in rat spinal cord slices} Glutamate-induced activation of Erk

Bath application of glutamate $(0.1-100 \mu \mathrm{M}$ for $30 \mathrm{~min} ; n=8-20$ slices) produced rapid increases in $\mathrm{p} 42 / 44$ Erk immunoreactivity in dorsal horn neurons of rats (Fig. 1). Neurons in both the superficial and deep dorsal horn were labeled (Fig. $1 B$ ). In the present study, we focused on labeling dorsal horn neurons in the superficial layers (laminas I-II) (Fig. 1C). Erk activation is dose-dependent (Fig. 1E), and application of glutamate at higher doses induced greater activation of Erk (Fig. $1 E$ ). The amount of activation also depends on the perfusion time; perfusion of 100 $\mu \mathrm{M}$ glutamate for $30 \mathrm{~min}$ produced maximal activation of Erk in spinal dorsal horn neurons (Fig. $1 F$ ). Glutamate-induced Erk activation was completely inhibited by a $10 \mathrm{~min}$ pretreatment with the selective MAPK kinase (MEK) inhibitor PD98059 (2' Amino- $3^{\prime}$-methoxyflavone; Calbiochem, La Jolla, CA) (50 $\mu \mathrm{M}$; $n=10$ slices) (Fig. $1 D, E)$.

Glutamate receptor-mediated activation of Erk

Activation of NMDA receptors contributes to Erk activation in the hippocampus (see Introduction). To test whether NMDA receptors are important for glutamate-induced activation of Erk in the rat dorsal horn, we pretreated slices with the selective NMDA receptor antagonist AP-5 (50 $\mu \mathrm{M} ; n=8$ slices $)$. AP-5 significantly decreased, but did not eliminate, the activation of Erk by glutamate $(100 \mu \mathrm{M})$ (Fig. $2 C, D, H)$, suggesting that 


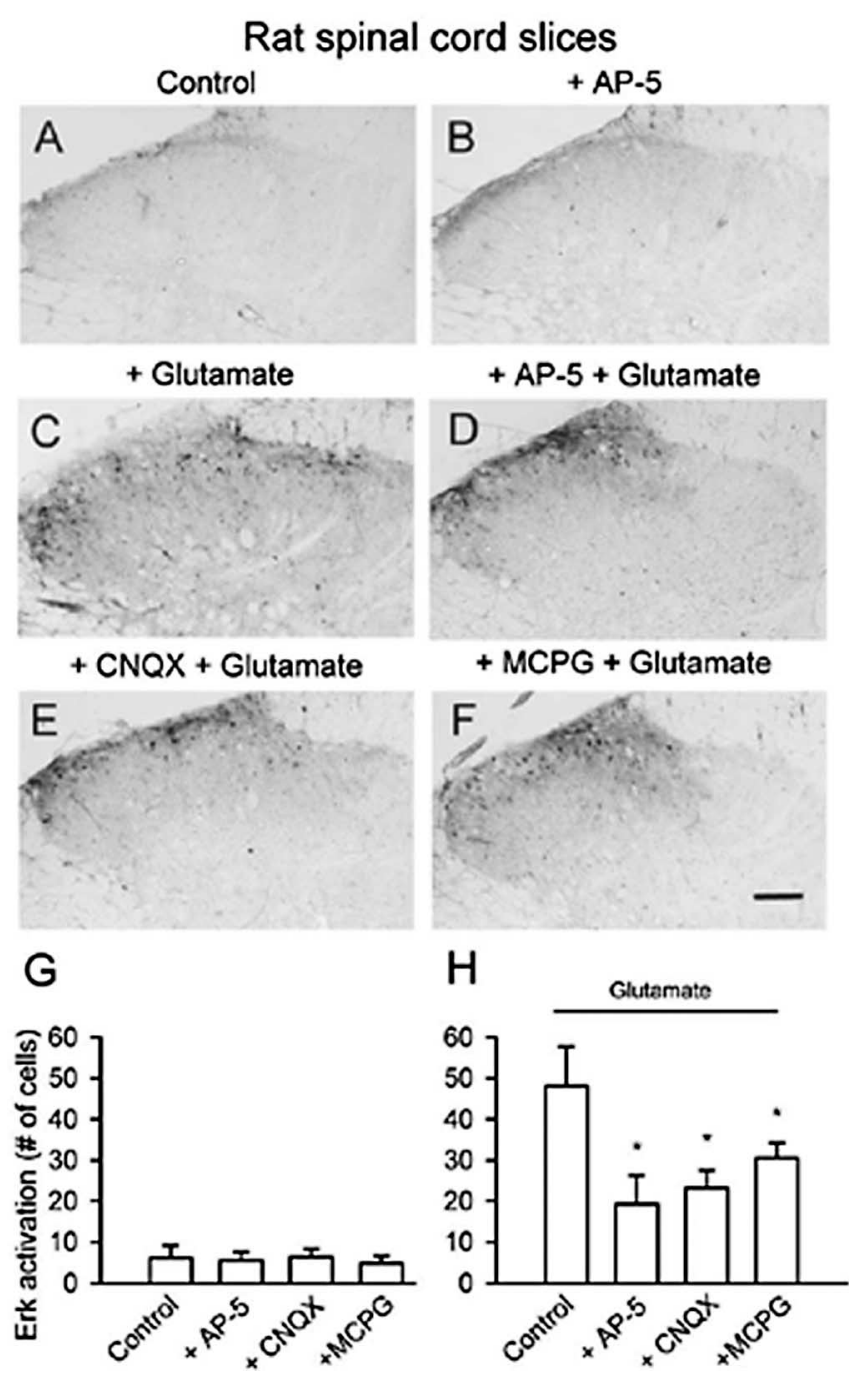

Figure 2. Pretreatment with glutamate receptor antagonists reduced glutamate-induced enhancement of pErk immunoreactivity in rat superficial dorsal horn. Pretreatment (10 min) with AP-5 (D), CNQX (E), and MCPG $(\boldsymbol{F})$ decreased the number of immunopositive cells for perk after glutamate exposure (100 $\mu \mathrm{m} ; 30 \mathrm{~min})$ (C). G, No obvious effect of the glutamate receptor antagonists on activation of Erk was observed (for a representative sample, see $\boldsymbol{B}$ ) compared with that of vehicle $(\boldsymbol{A})$. $\boldsymbol{H}$, Summary data of the effect of different antagonists on the attenuation of glutamate-induced phosphorylation of Erk in superficial dorsal horn neurons. * Significant difference compared with application of glutamate alone; $p<0.05$. Scale bar: $\boldsymbol{F}$ (for $\boldsymbol{A}-\boldsymbol{F}), 100 \mu \mathrm{m}$. Error bars indicate SEM.

NMDA receptors are critical for this activation. Bath application of NMDA ( $100 \mu \mathrm{M} ; 30 \mathrm{~min} ; n=6$ slices) also induced significant increases in pErk immunostaining in dorsal horn neurons in a pattern similar to that induced by glutamate. Because AP- 5 at this dose completely blocked NMDA receptor-mediated currents $(\mathrm{Li}$ and Zhuo, 1998) but not Erk activation in dorsal horn neurons, these results suggest that other types of glutamate receptors may be also involved in Erk activation.

To test whether AMPA/kainate receptor activation induces an increase in pErk immunoreactivity in neurons, we tested the effect of CNQX $(20 \mu \mathrm{M})$, a nonselective antagonist of AMPA and kainate receptors, on glutamate-induced Erk activation. A significant decrease in pErk immunostaining was observed in slices pretreated with CNQX ( $n=8$ slices) (Fig. $2 E, H$ ). Metabotropic glutamate receptors (mGluRs) are found in spinal dorsal horn neurons (Nakanishi, 1992). The contribution of mGluRs to glutamate-induced Erk activation was examined using the

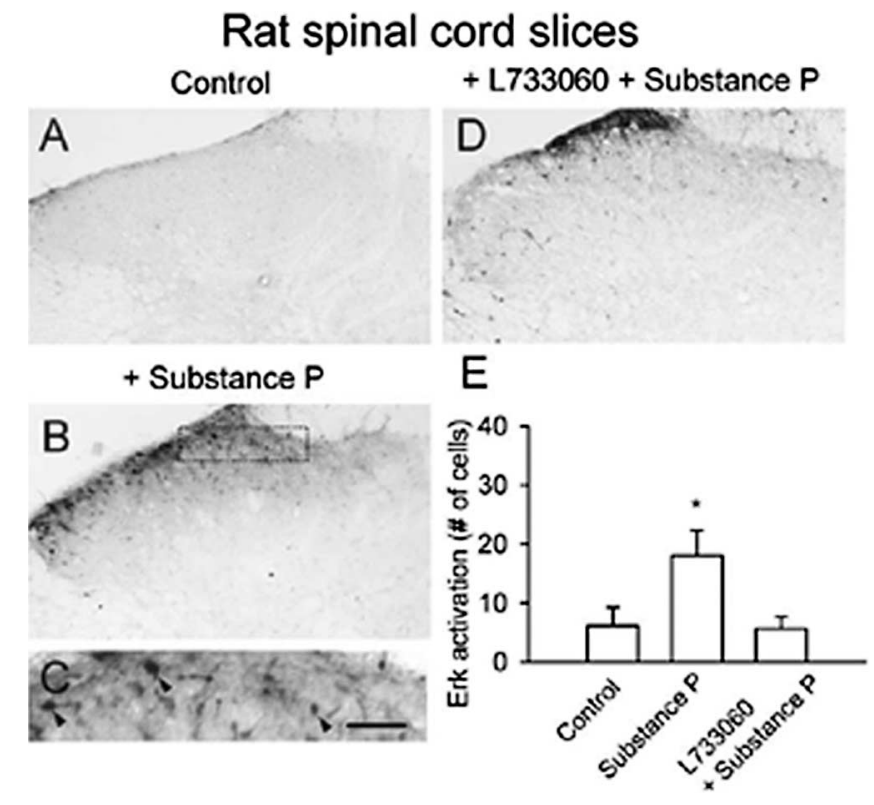

Figure 3. Activation of Erk by SP in adult rat spinal cord slices. Basal expression of pErk in ACSF-perfused slices $(\boldsymbol{A})$. Bath application of SP (10 $\mu \mathrm{m}$ for $30 \mathrm{~min}$ ) increased pErk immunoreactivity in dorsal horn neurons $(\boldsymbol{B})$. High magnification of the middle part of the superficial dorsal horn in $\boldsymbol{B}$ showing labeled neurons ( $\boldsymbol{C}$, arrowheads). This activation was inhibited by pretreatment with the NK1 receptor antagonist L-733060 (D). E, Summary data of pErk immunoreactivity in superficial dorsal horn. ${ }^{*}$ Significant difference compared with control; $p<0.05$. Scale bar: (in $C) A, B, D, 100 \mu \mathrm{m} ; C, 40 \mu \mathrm{m}$. Error bars indicate SEM.

mGluR receptor antagonist MCPG $(500 \mu \mathrm{M})$, which also resulted in decreased pErk immunostaining ( $n=8$ slices) (Fig. $2 F, H)$. Consequently, the mGluR activator tACPD $(200 \mu \mathrm{M})$ induced an elevation of pErk expression in dorsal horn neurons ( $18 \pm 3$ cells compared with $6 \pm 3$ cells in control slices; $p<0.05 ; n=6$ slices). In addition, no change in pErk immunoreactivity in the dorsal horn was observed after bath application of glutamate receptor antagonists alone (Fig. $2 B, G$ ), suggesting that these chemicals had no direct effects on activation of Erk.

SP-induced activation of Erk

SP acts as a neuropeptide transmitter between primary afferent fibers and dorsal horn neurons (Levine et al., 1993; Li and Zhuo, 2001). Bath application of $10 \mu \mathrm{M}$ SP induced pErk expression in superficial dorsal horn neurons and to a lesser extent in deep dorsal horn neurons ( $n=10$ slices) (Fig. $3 B, C, E)$. NK1 receptors mediated this effect of SP, because the selective NK1 receptor antagonist L-733060 (100 $\mu \mathrm{M})$ significantly reduced SP-induced Erk activation ( $n=9$ slices) (Fig. $3 D, E)$.

\section{Activation of Erk by endogenous neurotransmitters}

To test the contribution of glutamate and SP released endogenously from primary afferent fibers in Erk activation, we used the vanilloid receptor-1 agonist capsaicin, which causes the release of both SP and glutamate from primary afferent fibers (Szallasi and Blumberg, 1999). Capsaicin (1 $\mu \mathrm{M})$ produced a robust and intense activation of Erk in spinal dorsal horn neurons $(n=$ 10 slices) (Fig. 4 B). Capsaicin induced pErk expression mainly in superficial dorsal horn neurons (Fig. 4C). The effect of capsaicin is dependent on both glutamate and SP receptors. Pretreatment of slices with the combination of three different glutamate recep-

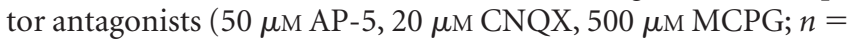
8 slices) significantly decreased capsaicin-induced Erk activation in rat spinal cord $(p<0.05)$ (Fig. $4 E$ ). The SP receptor antago- 


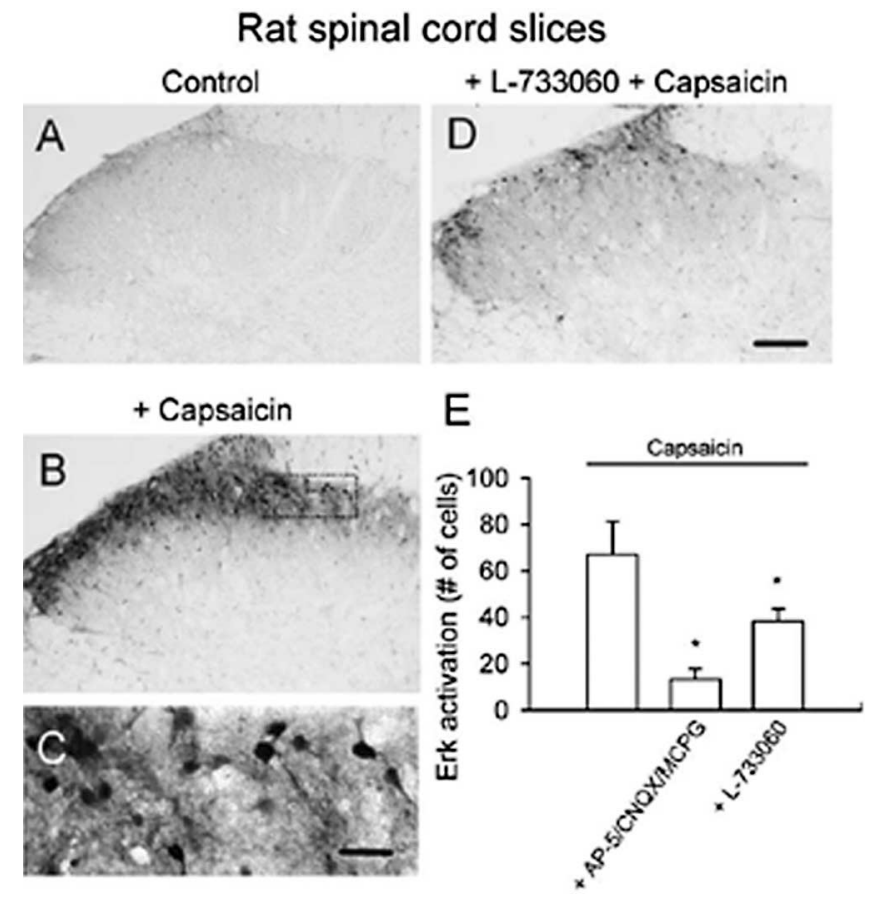

Figure 4. Activation of spinal Erk by capsaicin in rat spinal cord slices. Compared with control slices $(\boldsymbol{A})$, bath application of capsaicin (1 $\mu \mathrm{m}$ for $30 \mathrm{~min}$ ) increased intensity of pErk immunoreactivity in dorsal horn neurons. $\boldsymbol{B}$, A high-magnification image of the medial superficial dorsal horn in $\boldsymbol{B}$ is provided $(\boldsymbol{C})$. Immunostaining of $\mathrm{p}$ Erk was observed in cell bodies and their proximal dendrites. The Erk activation in superficial dorsal horn was significantly decreased by the NK1 receptor antagonist $L-733060(\boldsymbol{D}, \boldsymbol{E})$ or a combination of the three glutamate receptor antagonists $(\boldsymbol{E})$. ${ }^{*}$ Significant difference compared with application of capsaicin alone; $p<0.05$. Scale bar: (in D) $A, B, D, 100 \mu \mathrm{m}$; (in C) C, $50 \mu \mathrm{m}$. Error bars indicate SEM.

nist L-733060 also significantly decreased the activation by capsaicin $(n=6$ slices; $p<0.05)$ (Fig. $4 D, E)$.

\section{Activation of Erk by glutamate and SP in mouse spinal cord slices}

To identify whether a similar mechanism of Erk activation is also present in mouse, we used the same protocol to repeat some of the experiments performed in rat spinal cord slices. Glutamate (100 $\mu \mathrm{M}$ for $30 \mathrm{~min}$ ) induced activation of Erk in mice spinal cord slices ( $n=6$ slices) (Fig. $5 C, E, G)$. This increase was significantly reduced by pretreating slices with both of AP-5 $(50 \mu \mathrm{M})$ and CNQX $(20 \mu \mathrm{M})(n=7)$ (Fig. $5 G)$. Consistently, SP (10 $\mu \mathrm{M}$ for 30 min; $n=7$ slices) resulted in an increase of Erk immunoreactivity in superficial dorsal horn neurons (Fig. $5 B$ ), which was reduced by the pretreatment of L-733060 ( $n=9$ slices) (Fig. $5 G$ ). Enhancement of Erk immunoreactivity by bath application of capsaicin ( $1 \mu \mathrm{M}$ for $30 \mathrm{~min} ; n=8$ slices) (Fig. $5 D, F$ ) was completely inhibited by PD98059 (50 $\mu$ M; $n=8$ slices; $p<0.05$ ) (Fig. $5 G$ ). These findings further support that Erk activation is involved in both glutamate- and SP-mediated synaptic transmission in mouse spinal dorsal horn.

\section{Activation of Erk in dorsal horn neurons by} noxious stimulation

Does glutamate- or SP-induced Erk activation occur in dorsal horn neurons as a result of spinal nociceptive signaling during acute and persistent pain? To address this question, we performed experiments in awake animals to determine whether Erk is activated by different somatosensory stimuli. In naive animals,
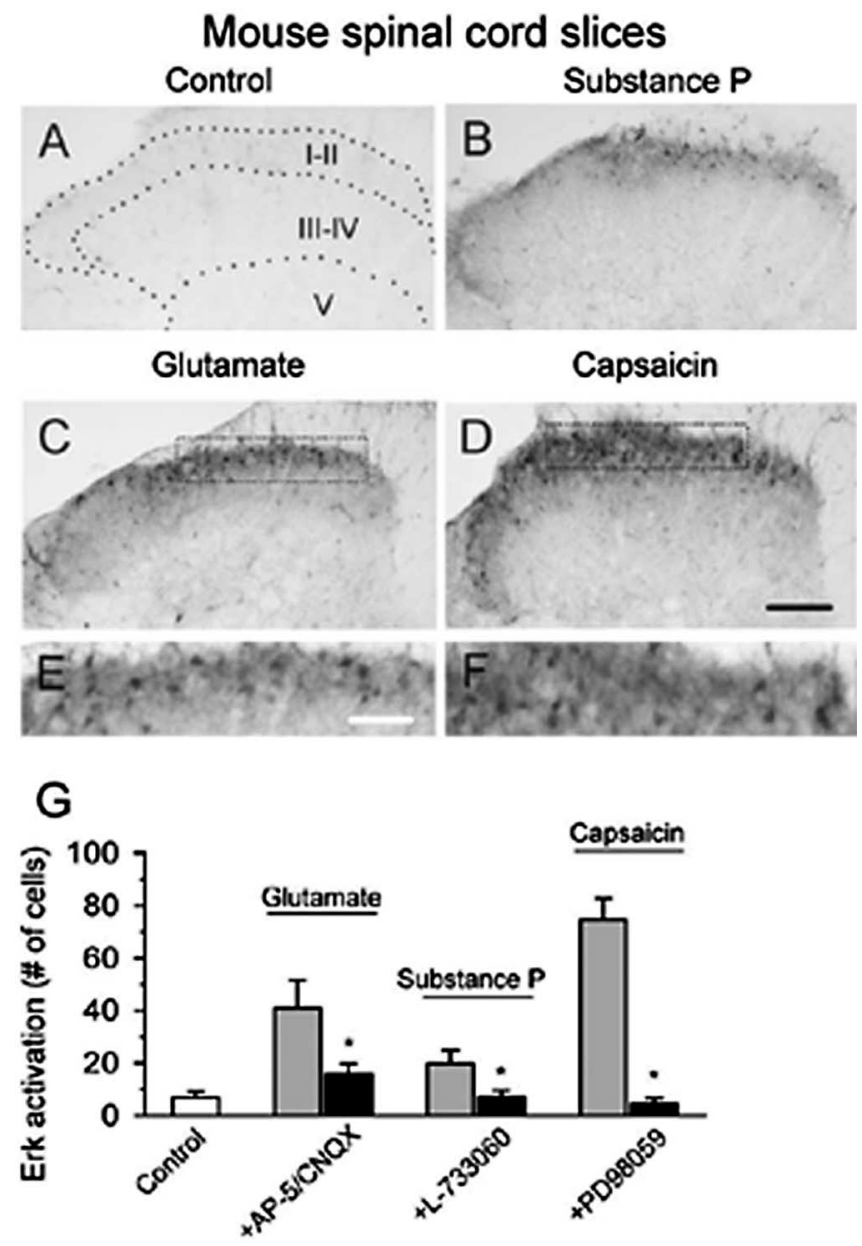

Figure 5. Representative activation of Erk in the dorsal horn from mouse spinal slices. Erk activation in the dorsal horn of spinal slices treated with bath application of SP (10 $\mu \mathrm{m}$ for 30 $\mathrm{min})(\boldsymbol{B})$, glutamate $(100 \mu \mathrm{m}$ for $30 \mathrm{~min})(\boldsymbol{C})$, or capsaicin $(1 \mu \mathrm{m}$ for $30 \mathrm{~min})(\boldsymbol{D})$ is shown. Higher magnifications of the superficial dorsal horn in $\boldsymbol{C}$ and $\boldsymbol{D}$ are provided in $\boldsymbol{E}$ and $\boldsymbol{F}$, respectively. $\boldsymbol{G}$, Summary data showed that the combination of AP-5 with CNQX attenuates the increase in activation of Erk by glutamate; SP-induced increase of Erk activation is completely blocked by the NK1 receptor antagonist L-733060 and pretreatment with the MEK inhibitor PD98059 blocked capsaicin-induced Erk activation. *Significant difference between groups with and without antagonists; $p<0.05$. Scale bars: (in $\boldsymbol{D}) \boldsymbol{A}-\boldsymbol{D}, 100 \mu \mathrm{m}$; (in $\boldsymbol{E}) \boldsymbol{E}, \boldsymbol{F}, 40 \mu \mathrm{m}$. Error bars indicate SEM.

only a few neurons ( $<3$ in each section) located within the superficial dorsal horn showed weak intensity of pErk immunoreactivity in rats or mice. We then tested whether innocuous mechanical brushing or acute noxious thermal heat activates Erk. As shown in Figures 6 and 7, neither repeated gentle brushing (12s; $n=4$ rats and 3 mice $)$ nor brief noxious heating of the hindpaw $\left(55^{\circ} \mathrm{C}\right.$; $12 \mathrm{~s} ; n=3$ rats and 3 mice) elicited Erk activation in spinal dorsal horn $45 \mathrm{~min}$ after stimulation. Furthermore, to detect possible earlier changes in vivo, we observed the level of immunostaining for pErk in spinal dorsal horn from 5 to 45 min after repeated brushing or noxious heat. There was no evidence of significant activation of Erk in this region $(n=2$ rats and 2 mice per time point) as compared with the control group.

Hindpaw injection of capsaicin induced obvious and distinct activation of Erk in the medial part of ipsilateral superficial dorsal horn within $15-45 \min$ ( $n=3$ rats and 3 mice per time point) (Figs. 6C,H, 7C,H, respectively). Expression of pErk was highest at $45 \mathrm{~min}$ after injection of capsaicin in both rats and mice, and 


\section{Erk activation in rat spinal cord in vivo Control Heat}

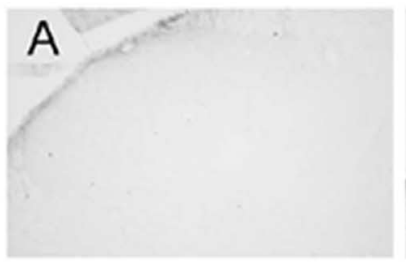

Capsaicin
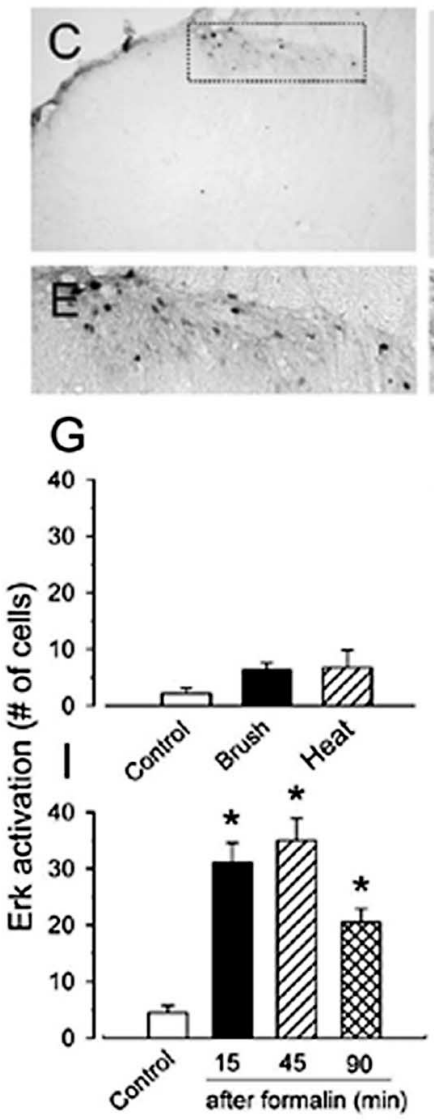

Figure 6. Activation of Erk by noxious stimulation in rat spinal dorsal horn. Representative pErk immunostaining in ipsilateral spinal dorsal horn from control and stimulated rats is shown. $\boldsymbol{A}$, Saline-treated control. B, Forty-five minutes after brief noxious thermal stimulation $\left(55^{\circ} \mathrm{C}\right.$; $12 \mathrm{~s}$ ) on a hindpaw skin. C, Hindpaw injection of capsaicin (100 $\mu \mathrm{g}$ for $15 \mathrm{~min}$ ) produced spinal Erk activation in the medial half of the superficial dorsal horn, in which additional enlargement $(\boldsymbol{E})$ showed a group of labeled neurons in this region. No obvious increase in pErk immunoreactivity was observed in deep dorsal horn. $\boldsymbol{D}$, Hindpaw injection of formalin $(5 \% ; 50 \mu l ; 45 \mathrm{~min})$ induced substantial increases in pErk immunoreactivity in the superficial and deep dorsal horn. $\boldsymbol{F}$, High magnification of the medial part of the superficial dorsal horn in $\boldsymbol{D}$ showing that a majority of labeled neurons have labeled dendrites located in this region. Graphical representations of change in average number of pErk-labeled neurons in the laminas I-II of ipsilateral spinal cord section after somatosensory stimuli in $\boldsymbol{A}-\boldsymbol{F}$ is shown in $\mathbf{G}-\boldsymbol{I}$. $\boldsymbol{G}$, Forty-five minutes after repeated brush or noxious heat $\left(55^{\circ} \mathrm{C}\right)$ on the hindpaw for $12 \mathrm{~s}$. Different time points after hindpaw injection of capsaicin $(\boldsymbol{H})$ or formalin $(\boldsymbol{I})$ into the plantar surface of the left hindpaw are shown. ${ }^{*} p<0.05$; compared with control animals. Scale bars: (in $\left.\boldsymbol{D}\right) \boldsymbol{A}-\boldsymbol{D}, 100 \mu \mathrm{m}$; (in $\boldsymbol{F}$ ) $\boldsymbol{E}, \boldsymbol{F}, 40 \mu \mathrm{m}$. Error bars indicate SEM.

returned to the baseline levels 90 min after injection of capsaicin ( $n=3$ rats and 3 mice) (Figs. $6 \mathrm{H}, 7 \mathrm{H}$, respectively). To test whether Erk is activated during persistent pain, we determined the effects of chemical and inflammatory pain on the activation of Erk in dorsal horn neurons. Vehicle (normal saline) injection

\section{Erk activation in mouse spinal cord in vivo Control \\ Heat}

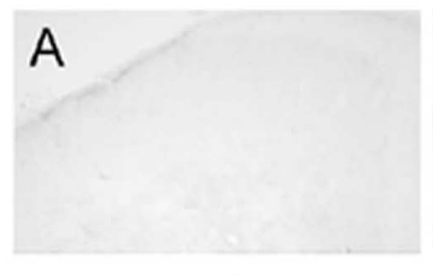

\section{Capsaicin}
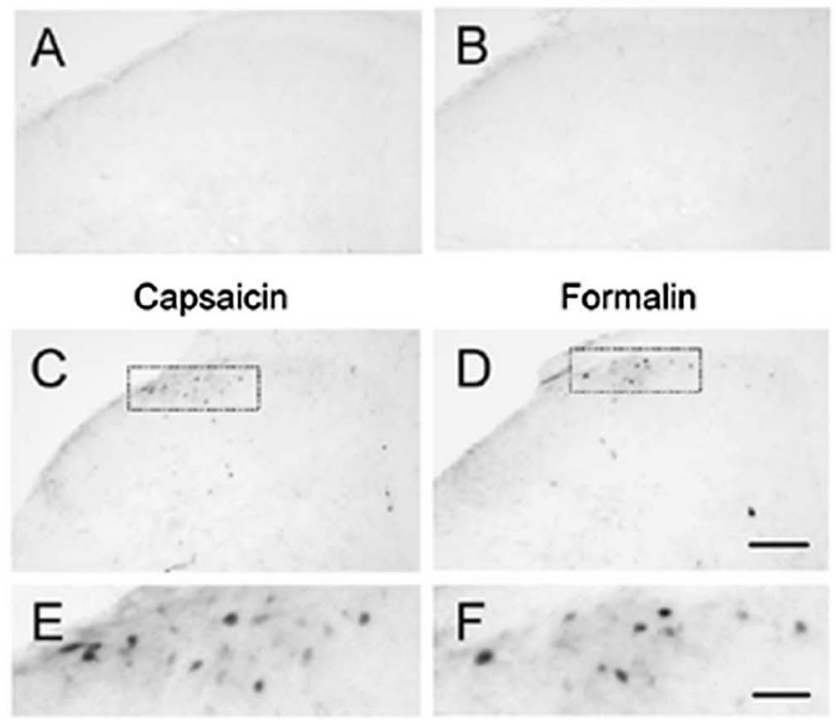

\section{Formalin}
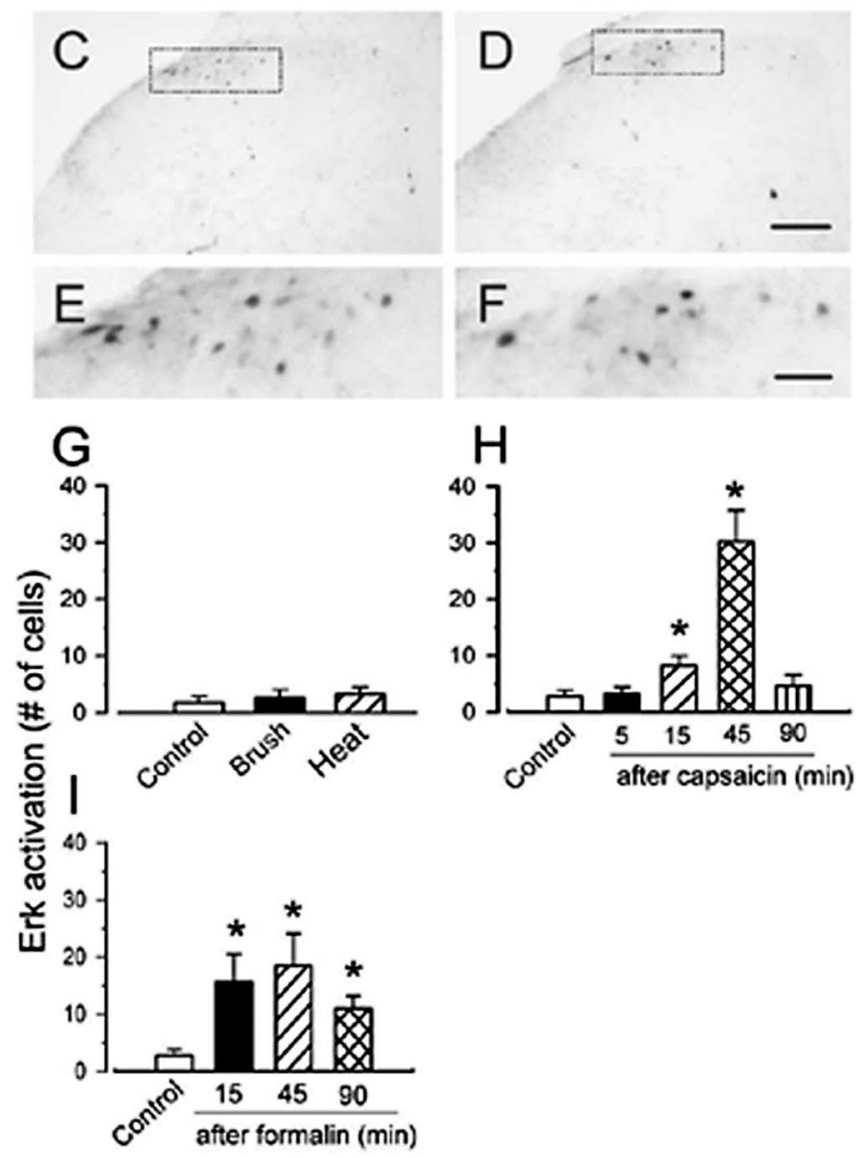

Figure 7. Activation of Erk by sensory stimulation in mouse spinal dorsal horn. Representative $p$ Erk immunostaining in ipsilateral spinal dorsal horn from control and stimulated mice are shown. $\boldsymbol{A}$, Control. $\boldsymbol{B}$, Brief noxious heat $\left(55^{\circ} \mathrm{C} ; 12 \mathrm{~s}\right)$ did not increase in pErk immunoreactivity. A similar pattern of Erk activation was observed at $45 \mathrm{~min}$ after injection of capsaicin $(10 \mu \mathrm{g})(\boldsymbol{C})$ and $5 \%$ formalin $(10 \mu l)(\boldsymbol{D}) . \boldsymbol{E}, \boldsymbol{F}$, A higher magnification image of the superficial dorsal horn in $\boldsymbol{C}$ and $\boldsymbol{D}$ respectively, with obviously labeled neurons. Graphical representations of changes in the average number of pErk-labeled neurons in the laminas I-II of the ipsilateral spinal cord section after somatosensory stimuli in $\boldsymbol{A}-\boldsymbol{F}$ are shown in $\mathbf{G}-\mathbf{I}$. $\mathbf{G}$, Forty-five minutes after repeated brushing or noxious heat $\left(55^{\circ} \mathrm{C}\right)$ on the hindpaw for $12 \mathrm{~s}$. Different time points after subcutaneous injection of capsaicin $(\boldsymbol{H})$ or formalin $(\boldsymbol{I})$ into the plantar surface of the left hindpaw, respectively, are shown. ${ }^{*} p<0.05$; compared with control animals. Scale bars: (in $\boldsymbol{D}$ ) $\boldsymbol{A}-\boldsymbol{D}, 100 \mu \mathrm{m}$; (in $\boldsymbol{F}) \boldsymbol{E}, \boldsymbol{F}, 30 \mu \mathrm{m}$. Error bars indicate SEM.

into the hindpaw induced lesser or no pErk. However, formalin (5\%) caused significant activation of Erk in both superficial and deep dorsal horn neurons in the ipsilateral spinal cord at $15 \mathrm{~min}$ after the injection $[n=4$ rats (Fig. $6 D, F, I$ ); $n=3$ mice (Fig. $7 D, F, I)]$. Similar to capsaicin, peak pErk expression occurred at $45 \mathrm{~min}$ after the formalin injection and remained increased for at least $90 \min$ ( $n=4$ rats and 3 mice) (Figs. 6I, 7I, respectively). 

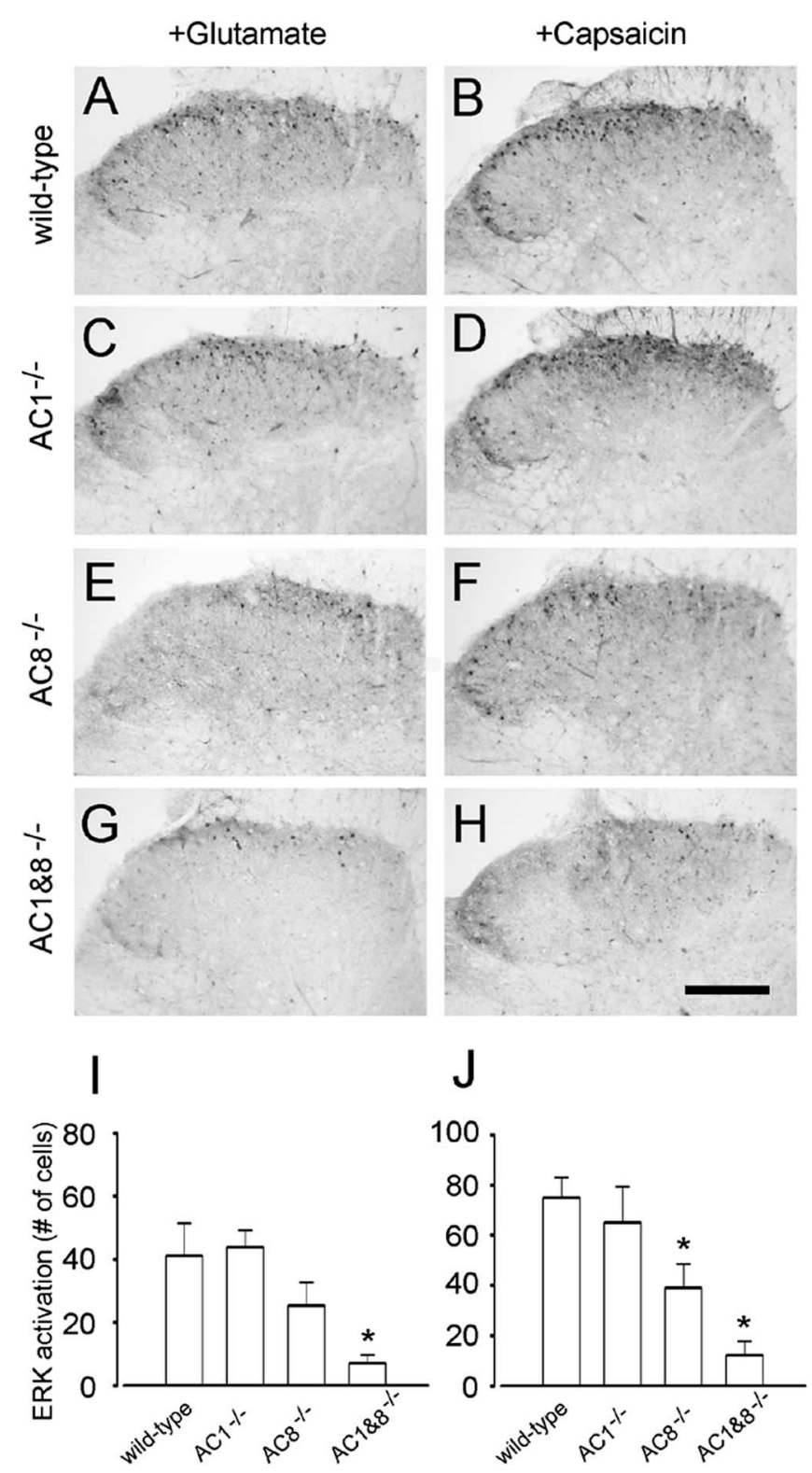

Figure 8. Activation of Erk by glutamate and capsaicin in genetic mice spinal cord slices. Bath application of glutamate (100 $\mu \mathrm{m}$ for $30 \mathrm{~min} ; \boldsymbol{A}, \boldsymbol{C}, \boldsymbol{E}, \boldsymbol{G}$ ) or capsaicin (1 $\mu \mathrm{m}$ for $30 \mathrm{~min} ; \boldsymbol{B}, \boldsymbol{D}, \boldsymbol{F}$, $\boldsymbol{H}$ ) induced expression of pErk in superficial dorsal horn from WT $(\boldsymbol{A}, \boldsymbol{B}), A C 1(\boldsymbol{C}, \boldsymbol{D})$, or $A C 8$ knock-out $(\boldsymbol{E}, \boldsymbol{F})$ but not $A C 1 \& 8$ DKO mice $(\boldsymbol{G}, \boldsymbol{H})$. I, J, Summary data showing variation of $p$ Erk expression in different genetic knock-out mice. ${ }^{*} p<0.05$, compared with WT groups. Scale bar: (in $\boldsymbol{H}) \boldsymbol{A}-\boldsymbol{H}, 100 \mu \mathrm{m}$. Error bars indicate SEM.

\section{Adenylyl cyclases 1 and 8 contribute to the activation of Erk in dorsal horn neurons}

In vitro spinal cord slices

The cAMP and Erk pathways cross-talk in many regions of the CNS (see Introduction). We wanted to test whether the activation of cAMP occurs upstream of Erk activation in dorsal horn neurons. First, we tested the effects of glutamate application on Erk activation in WT and mice lacking $A C 1$ or $A C 8$. Genetic deletion of both $A C 1$ and $A C 8$ did not significantly change the basal expression of pErk in the superficial dorsal horn neurons. Bath application of glutamate $(100 \mu \mathrm{M}$ for $30 \mathrm{~min})$ increased pErk immunoreactivity in dorsal horn neurons of WT mice $(n=$ 4 mice) (Fig. $8 A, I$ ). These immunopositive neurons were located mainly in the superficial dorsal horn. Glutamate-induced Erk activation was also significantly affected in the dorsal horn neurons of $A C 8$ but not $A C 1$ knock-out mice ( $n=4$ mice) (Fig. $8 C, E, I)$, indicating that single deletion of $A C 1$ is not sufficient to abolish glutamate induced Erk activation. Because AC1 and AC8 are both activated by calcium-CaM, we performed experiments using the double knock-out mice lacking $A C 1$ and $A C 8$ to further examine the possible compensatory effects between $\mathrm{AC} 1$ and AC8. As shown in Figure 8G,I, activated Erk was significantly reduced in the superficial dorsal horn of the spinal cord $(n=8$ mice), as compared with WT littermates ( $n=8$ mice).

Next, we examined the effects of capsaicin in vitro. In WT ( $n=$ 8 mice), bath application of capsaicin ( $1 \mu \mathrm{M}$ for $30 \mathrm{~min})$ induced significant activation of Erk in superficial dorsal horn neurons, and less activation was found in deeper dorsal horn neurons (Fig. $8 B$ ). Consistent with the results from rat, capsaicin-induced activation of Erk in WT mice was greater than in glutamate-treated slices and was more distributed in the superficial dorsal horn. It is possible that glutamate and capsaicin may activate different populations of dorsal horn neurons in the spinal cord. Genetic deletion of $A C 8$ ( $n=4$ mice) but not $A C 1$ ( $n=4$ mice) significantly reduced capsaicin-induced pErk in superficial dorsal horn neurons (Fig. $8 D, F, J)$. In $A C 1 \& 8 \mathrm{DKO}$ animals ( $n=8$ mice), greater reduction of Erk activation was found (Fig. $8 \mathrm{H}, \mathrm{J}$ ), providing further support for the important functions of AC1 and AC8 in dorsal horn neurons.

\section{In vivo experiments}

Next, to examine whether AC1 and AC8 contribute to the activation of Erk by peripheral inflammation, we injected formalin subcutaneously in WT mice. We found that formalin induced a similar amount of activation of Erk in spinal superficial dorsal horn neurons ( $n=6$ mice) (Fig. 9A). In $A C 1$ or $A C 8$ knock-out mice, pErk induced by hindpaw formalin was not significantly affected ( $n=6$ each) (Fig. $9 B$ ). In contrast, pErk induced by formalin was completely blocked in $A C 1 \& 8 \mathrm{DKO}$ mice $(n=6)$ (Fig. 9A,B). Furthermore, a double immunostaining for both neuronal marker NeuN and pErk clearly showed that Erk activation was present in spinal dorsal horn neurons at $15 \mathrm{~min}$ after hindpaw formalin injection ( $n=4$ mice) (Fig. 9C).

\section{Genetic elimination of adenylyl cyclases does not affect the expression of Erk in dorsal spinal cord}

To determine whether the decreased levels of pErk observed in $A C 1, A C 8$, and $A C 1 \& 8 \mathrm{DKO}$ mice after inflammation or chemicals are attributable to a decrease in basal expression of Erk, we performed a Western blot analysis to estimate the levels of Erk in the dorsal half of the lumbar spinal cord. The results showed that the levels of Erk were not significantly different in $A C 1 \mathrm{KO}, A C 8$ $\mathrm{KO}$, or $A C 1 \& 8 \mathrm{DKO}$ from the WT animals ( $n=3$ mice per group; $p>0.05$ ) (Fig. 9D). This indicates that the expression levels of Erk in the dorsal horns of the spinal cord were not affected by the genetic deletion of $A C 1, A C 8$, or a combination of both, and indicates that the changes in pErk levels in the knock-out mice were the result of the absence of adenylyl cyclase enzymes.

\section{Involvement of PKA in Erk activation in spinal cord slices}

The Erk pathways cross-talk with PKA in many regions of the CNS (see Introduction). We wanted to test whether activation of PKA may occur upstream from Erk activation in dorsal horn neurons. We observed that the adenylyl cyclase activator forskolin ( $10 \mu \mathrm{M} ; 30 \mathrm{~min} ; n=16$ slices in rats; $n=10$ in mice) induced substantial enhancement of pErk immunoreactivity in the super- 

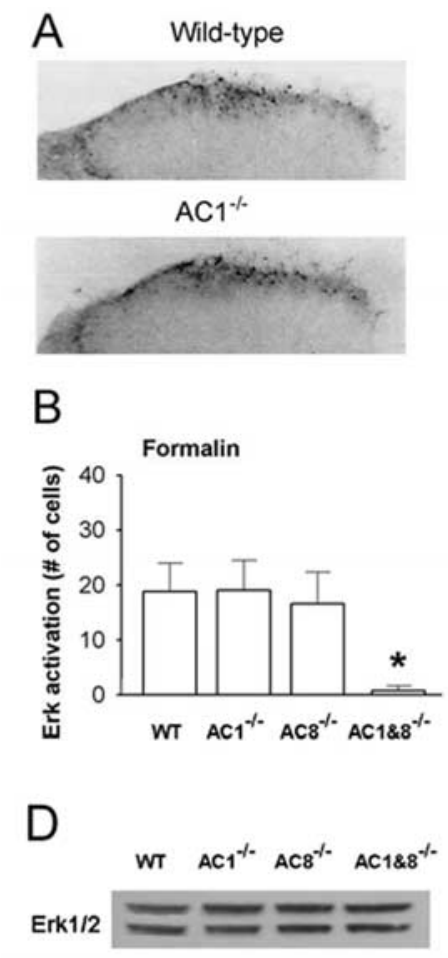

B-tubulin
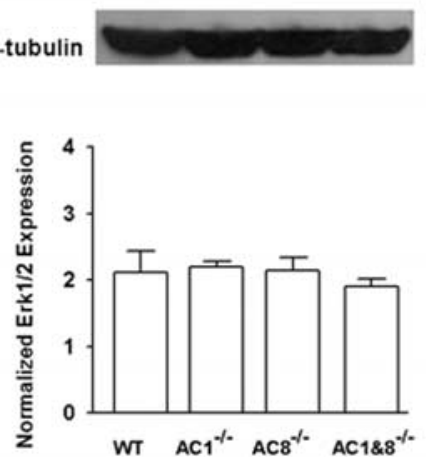

Figure 9. Erk expression in the spinal dorsal horn of $A C 1, A C 8$, and $A C 1 \& 8 D K 0$ mice. Different patterns of pErk expression in AC1\&8DKO mice compared with WT mice. $\boldsymbol{A}$, pErk immunoreactivity in dorsal horn of knock-out mice. Scale bar, $50 \mu \mathrm{m}$. The value $n=6$ mice per group. $\boldsymbol{B}$, Graphical representation of the number of immunoreactive cells at $45 \mathrm{~min}$ after injection of formalin ( $n=6$ mice per group; ${ }^{*} p<0.05$ ). C, Double immunostaining showed Erk activation in superficial dorsal horn neurons of WT mice labeled by NeuN (arrows; $n=4$ mice) at 15 min after hindpaw formalin injection. Scale bar, $20 \mu \mathrm{m}$. D, Representative Western blots of Erk expression in dorsal horn homogenates in $A C 1, A C 8, A C 1 \& 8 D K 0$, and WT mice. The normalized Erk expression between all groups was unchanged ( $n=3$ mice per group; $p>0.05$ ). Error bars indicate SEM.

ficial dorsal horn of both rat (Fig. 10C) and mouse (Fig. 10D), compared with control animals (Fig. 10A,B).

\section{Pharmacological experiments}

To examine whether cAMP production in the spinal cord contributes to the maintenance of behavioral allodynia, forskolin was injected into the intrathecal space of the lumbar spinal cord region. Pretreatment with intrathecal injection of forskolin $30 \mathrm{~min}$ before the hindpaw CFA injection in AC1\&8 DKO animals significantly induced mechanical allodynia on the ipsilateral side in $A C 1 \& 8$ DKO mice ( $n=4$ mice per group) (Fig. $10 F)$. This rescued mechanical allodynia was present from day 1 (percentage response: day 1 , forskolin $75 \pm 15$, vehicle $30 \pm 10, p<0.05$; day 3 , forskolin $80 \pm 14.1$, vehicle $40 \pm 14.1, p<0.05$ ) and continued

\section{Spinal cord slices \\ Rat \\ Control \\ Mouse}
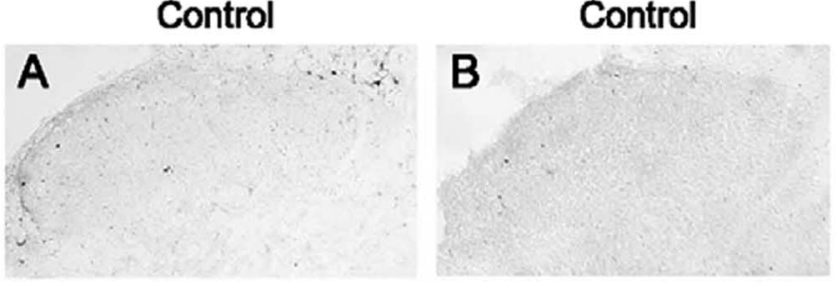

+ Forskolin
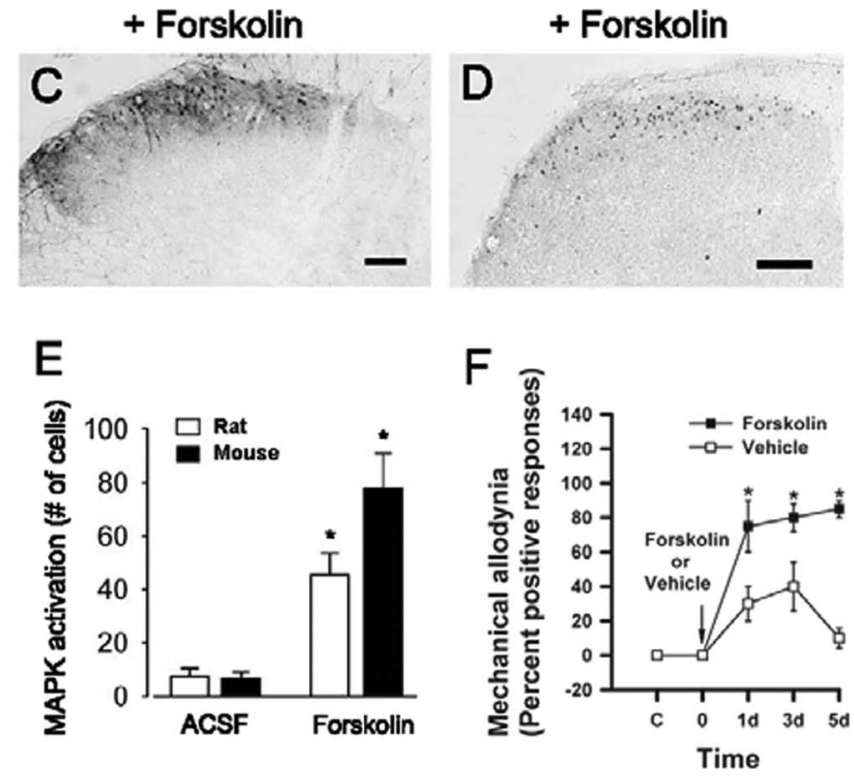

Figure 10. Activation of Erk by forskolin in rat and mouse spinal cord slices. Forskolininduced $\mathrm{pErk}$ immunoreactivity in dorsal horn neurons in spinal cord slices from adult rats $(\boldsymbol{C})$ and mice ( $\boldsymbol{D}$ ) compared with the control ( $\boldsymbol{A}$ and $\boldsymbol{B}$, respectively) is shown. Pooled data from rats and mice are shown in $\boldsymbol{E}$. $\boldsymbol{F}$, Pretreatment with an intrathecal injection of forskolin ( $12 \mathrm{nmol}$ ) 30 min before the unilateral hindpaw injection of CFA in $A C 1 \& 8$ DKO mice rescued mechanical allodynia ( $n=4$ mice in each group). Behavioral responses to the von Frey stimulation (filament $N_{0} 2.44$ ) on the dorsum of the ipsilateral hindpaw are plotted against time. Mechanical allodynia was tested on days 1, 3, and 5. Asterisks indicate significant differences compared with control; * $p<0.05 ;{ }^{* *} p<0.001$. Scale bars, $100 \mu \mathrm{m}$. Error bars indicate SEM.

to persist at a higher magnitude by day 5 (forskolin $85 \pm 5$; vehicle $10 \pm 5.8 ; p<0.001)$. Because it has been shown previously that blockade of Erk inhibits cAMP response element-binding protein (CREB) activation in spinal dorsal horn (Kawasaki et al., 2004), the forskolin-induced behavioral allodynia in AC1\&8 DKO mice indicates that Erk-mediated activation is intact in these animals and contributes to the behavioral allodynia. Thus, an increase in cAMP in spinal cord in AC1\&8 DKO mice can activate downstream pathways, including Erk, to rescue the behavioral phenotype.

Activation of Erk contributes to LTP in dorsal horn neurons To examine the role of Erk for the induction of spinal LTP, we performed whole-cell patch-clamp recordings from neurons in the superficial dorsal horn of the spinal cord. Fast EPSCs were obtained by delivering focal electrical stimulation to the dorsal root entry zone (Li and Zhuo, 1998) (Fig. 11 A). LTP was induced with 80 paired presynaptic pulses at $2 \mathrm{~Hz}$ with postsynaptic depolarization at $+30 \mathrm{mV}$ (referred to in Figure $11 \mathrm{~B}$ as paired training) within 5 min after establishing the whole-cell configuration to avoid washout of intracellular contents that are critical for the establishment of synaptic plasticity (Ikeda et al., 2003; 

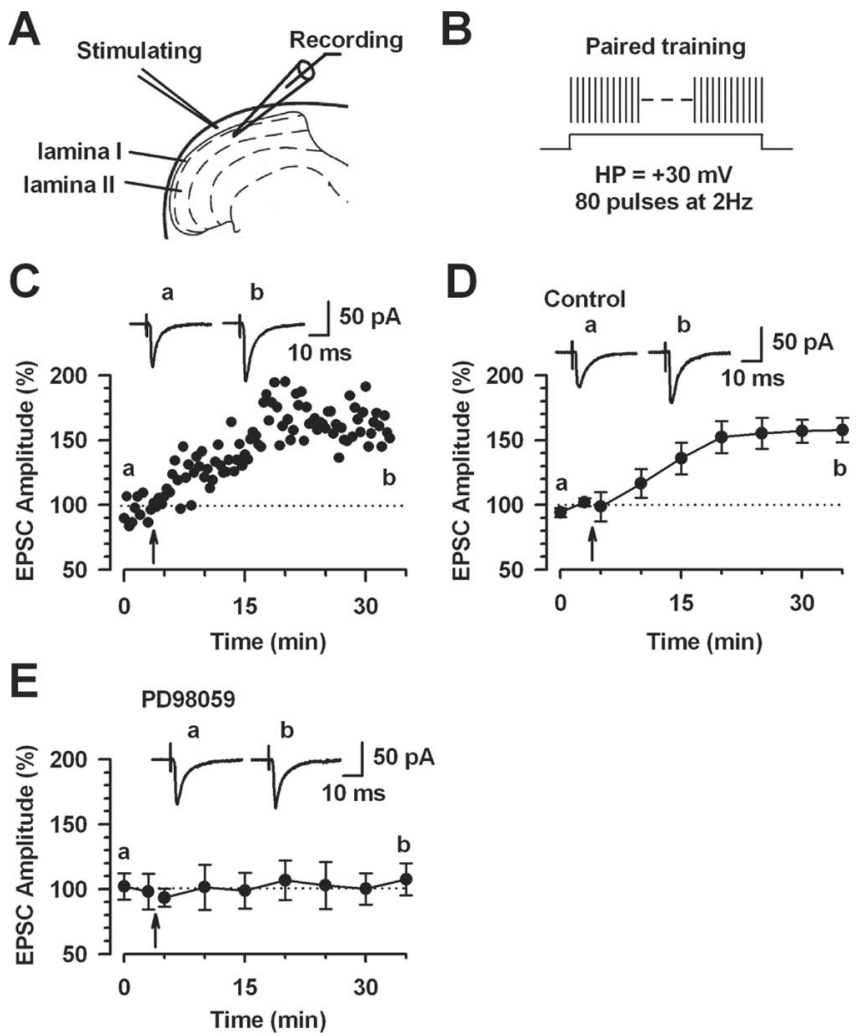

Figure 11. Activation of Erk for the induction of $L T P$ in the superficial dorsal horn neurons. $A$, Diagram of a slice showing the placement of a whole-cell patch-clamp recording and a stimulation electrode in the superficial dorsal horn of the spinal cord. $\boldsymbol{B}$, Schematic illustrating the induction protocol consisting of 80 pulses at $2 \mathrm{~Hz}$ while holding at $+30 \mathrm{mV}$ (paired training). $C$, LTP was induced by paired training in the superficial dorsal horn neurons. $D$, Summary result of the LTP experiments under control conditions ( $n=9$ neurons). EPSC responses were averaged over 5 min intervals. $\boldsymbol{E}$, The MEK inhibitor PD98059 (50 $\mu \mathrm{m})$ in the intracellular solution completely blocked LTP induction ( $n=7$ neurons). EPSC responses were averaged over 5 min intervals. $\boldsymbol{C}-\boldsymbol{E}$, Traces show averages of six EPSCs 3 min before (a) and $25 \mathrm{~min}$ after (b) the paired training (arrow). The dashed line indicates the mean basal synaptic responses. Error bars indicate SEM.

Zhao et al., 2005). The paired training produced a significant, long-lasting potentiation of synaptic responses in control slices $(157.8 \pm 9.4 \% ; n=9 ; p<0.05$ compared with baseline responses) (Fig. 11C,D). We then tested whether LTP induced by paired training is prevented by MEK inhibitor PD98059. Postsynaptic injection of PD98059 $(50 \mu \mathrm{M})$ in the intracellular solution completely blocked the induction of LTP (107.4 \pm $12.4 \% ; n=7 ; p>0.05$ compared with baseline response) (Fig. $11 E)$. These results suggest that Erk activity is required for the induction of LTP in the superficial dorsal horn neurons.

\section{Discussion}

Erk has been implicated as a mediator of plastic changes at glutamatergic synapses in several supraspinal areas of the CNS (English and Sweatt, 1996; Obrietan et al., 1998; Roberson et al., 1999). Our results provide the first genetic evidence to link calcium-CaM-stimulated AC1 and AC8 to Erk activation in spinal cord dorsal horn neurons. Contribution of AC1 and AC8 to Erk activation induced by tissue inflammation demonstrates that the ACs-Erk pathway may contribute to persistent inflammatory pain. Spinal dorsal horn neurons receive nociceptive information from the periphery via release of glutamate and SP from primary afferent fibers. The present study shows that activation of glutamate or SP receptors can activate Erk in dorsal horn neurons in spinal slices of adult rats and mice. Tissue injury, but not innocuous sensory stimulation or acute noxious heat, activated Erk in dorsal horn neurons in vivo. Our results are consistent with a report by Ji et al. (1999) in adult rats, providing strong evidence that an Erk cascade may contribute to the spinal signal pathways underlying persistent pain in both rats and mice. Recent experiments by Kawasaki et al. (2004) showed that PKA and PKC contribute to C-fiber-induced Erk activation in dorsal horn neurons leading to spinal sensitization, an underlying mechanism for the development of persistent pain after injury. Therefore, it can be envisaged that calcium-CaM-stimulated AC1 and AC8 act upstream of both PKA and PKC to mediate activation of Erk in dorsal horn neurons. Together, the present work demonstrates the AC1/AC8 dependency of the Erk signaling pathway in spinal dorsal horn neurons.

NMDA receptors are important mediators of some forms of long-term synaptic plasticity, including long-term potentiation and long-term depression (Bliss and Collingridge, 1993). Here, we found that activation of spinal NMDA receptors was important for the activation of Erk in dorsal horn neurons in spinal cord slices similar to the previous reports (Impey et al., 1999). Consistently, Ji et al. (1999) reported that the blockade of spinal NMDA receptors significantly decreased the activation of Erk induced by peripheral injection of capsaicin. These in vitro and in vivo studies suggest that NMDA receptor-dependent Erk pathways are activated after tissue injury. Interestingly, similar to the previous study (Ji et al., 1999), our results also indicate that other glutamate receptors may also contribute to the activation of Erk. In our studies, bath application of other glutamate receptor antagonists, including an AMPA/kainate and a metabotropic receptor antagonist, significantly decreased the glutamate-induced activation of Erk. In addition, a metabotropic glutamate receptor agonist activated Erk in dorsal horn neurons. Activation of ionotropic or metabotropic glutamate receptors can cause increases in postsynaptic calcium levels, either directly or indirectly and, thus, activate calcium-dependent signaling cascades (Gu et al., 1996; Engelman et al., 1999).

SP plays dual roles in spinal nociceptive transmission as a transmitter of primary afferent fibers and a modulator of local and descending pathways. It is known that the activation of the NK1 receptor increases intracellular calcium concentrations (Shen and North, 1992; Otsuka and Yoshioka, 1993; Heath et al., 1994). In the present study, we found that SP activated Erk in spinal dorsal horn neurons, and a selective NK1 receptor antagonist could block the effect of SP. These results indicate that, together, glutamate and SP may play important roles in dorsal horn sensory plasticity through Erk activation. Although bath application of SP may mimic the events related to sensory transmission as well as spinal modulation, the observations made with bath application of capsaicin suggest that endogenous SP released from central terminals of capsaicin-sensitive primary afferent fibers activates Erk in dorsal horn neurons. Pharmacological experiments using an NK1 receptor antagonist supported this consideration.

Consistent with findings that AC agonists activate Erk in hippocampal neurons (Martin et al., 1997; Impey et al., 1998), our in vivo and in vitro results supports the importance of AC1 and AC8 in spinal Erk activation. In the case of chemical activation of Erk by glutamate or capsaicin, we found that deletion of $A C 8$ but not $A C 1$ significantly reduced pErk in superficial dorsal horn neurons. The possible explanation may be that $\mathrm{AC} 1$ in the absence of AC8 may not be fully functional in slice preparations. Thus, it appears that AC1 may have a functional dependency on AC8 in 
vitro. Whereas such a difference was observed only in AC8 knockout spinal cord slices, the results from $A C 1 \& 8 \mathrm{DKO}$ mice were consistent in both in vivo and in vitro. Considering that $\mathrm{AC} 1$ is more sensitive to calcium than AC8, these results suggest that $\mathrm{AC} 1$ and $\mathrm{AC} 8$ may couple to pErk in a differential manner in dorsal horn neurons. The greater effects of $A C 1 \& 8$ DKO mice suggest that $\mathrm{AC} 1$ and $\mathrm{AC} 8$ may act synergistically upstream to the Erk. Unlike in vitro studies, deletion of $A C 1$ or $A C 8$ alone is not sufficient to reduce Erk activation in vivo, although reduced behavioral nociceptive responses were observed previously (Wei et al., 2002). These findings suggest that one cannot simply correlate Erk activity in spinal dorsal horn neurons with behavioral responses to peripheral inflammation.

Two likely candidates of intracellular messengers upstream from Erk are cAMP and PKC. PKC, which is known to be important in the enhancement of dorsal horn neuron excitability and spinal synaptic facilitation (Gerber et al., 1989; Hori et al., 1996; Lin et al., 1996; Li et al., 1999), could also activate Erk in dorsal horn neurons. We believe that future studies using a combination of genetically manipulated mice and pharmacological agents should help to decipher the signaling pathways connecting the activation of glutamate and SP receptors to postsynaptic activation of Erk in spinal dorsal horn neurons.

The influences of Erk in glutamatergic synaptic plasticity have been reported in the CNS. In the hippocampus, Erk is activated by strong tetanic stimulation that induces long-lasting synaptic potentiation in the hippocampus (English and Sweatt, 1996; Obrietan et al., 1998). Activation of Erk is required for synaptic potentiation, and inhibition of Erk decreased the magnitude of LTP induced by multiple-train tetanic stimulation (Impey et al., 1998). In the prefrontal cortex, Otani et al. (1999) found that activation of Erk was important for another type of synaptic plasticity, long-term depression. Other structures within the CNS, such as the anterior cingulate cortex and insular cortex, may also contribute to behavioral responses to noxious stimuli (Zhuo, 2004). In the present study, we demonstrate that tissue inflammation induced activation of Erk in spinal dorsal horn neurons in both adult rats and mice. Our present study also shows that postsynaptic inhibition of the Erk pathway blocked LTP in superficial dorsal horn neurons. Behavioral and pharmacological results (Ji et al., 1999) showed that the activation of spinal Erk contributes to behavioral responses to subcutaneous injection of formalin. Our present results using $A C 1$ and $A C 8$ knock-out mice, together with previous reports of reduced behavioral nociceptive responses in these mice, consistently suggest that spinal Erk activation in the superficial dorsal horn of the spinal cord can be physiologically related to spinal sensitization and persistent pain after injury.

\section{References}

Adwanikar H, Karim F, Gereau IV RW (2004) Inflammation persistently enhances nocifensive behaviors mediated by spinal group I mGluRs through sustained ERK activation. Pain 111:125-135.

Bliss TV, Collingridge GL (1993) A synaptic model of memory: long-term potentiation in the hippocampus. Nature 361:31-39.

Chetkovich DM, Sweatt JD (1993) nMDA receptor activation increases cyclic AMP in area CA1 of the hippocampus via calcium/calmodulin stimulation of adenylyl cyclase. J Neurochem 61:1933-1942.

Coderre TJ, Katz J, Vaccarino AL, Melzack R (1993) Contribution of central neuroplasticity to pathological pain: review of clinical and experimental evidence. Pain 52:259-285.

Dubner R, Basbaum AI (1994) Spinal dorsal horn plasticity following tissue or nerve injury. In: Textbook of pain, Ed 3 (Wall PD, Melzack R, Bonica JJ, eds), pp 230-233. New York: Churchill Livingstone.

Engelman HS, Allen TB, MacDermott AB (1999) The distribution of neu- rons expressing calcium-permeable AMPA receptors in the superficial laminae of the spinal cord dorsal horn. J Neurosci 19:2081-2089.

English JD, Sweatt JD (1996) Activation of p42 mitogen-activated protein kinase in hippocampal long term potentiation. J Biol Chem 271:24329-24332.

Frey U, Huang YY, Kandel ER (1993) Effects of cAMP simulate a late stage of LTP in hippocampal CA1 neurons. Science 260:1661-1664.

Gerber G, Kangrga I, Ryu PD, Larew JS, Randic M (1989) Multiple effects of phorbol esters in the rat spinal dorsal horn. J Neurosci 9:3606-3617.

Gille H, Sharrocks AD, Shaw PE (1992) Phosphorylation of transcription factor p62TCF by MAP kinase stimulates ternary complex formation at c-fos promoter. Nature 358:414-417.

Gu JG, Albuquerque C, Lee CJ, MacDermott AB (1996) Synaptic strengthening through activation of $\mathrm{Ca}^{2+}$-permeable AMPA receptors. Nature 381:793-796.

Heath MJ, Womack MD, MacDermott AB (1994) Substance P elevates intracellular calcium in both neurons and glial cells from the dorsal horn of the spinal cord. J Neurophysiol 72:1192-1198.

Hori Y, Endo K, Takahashi T (1996) Long-lasting synaptic facilitation induced by serotonin in superficial dorsal horn neurones of the rat spinal cord. J Physiol (Lond) 492:867-876.

Hu HJ, Gereau IV RW (2003) ERK integrates PKA and PKC signaling in superficial dorsal horn neurons. II. Modulation of neuronal excitability. J Neurophysiol 90:1680-1688.

Hu HJ, Glauner KS, Gereau IV RW (2003) ERK integrates PKA and PKC signaling in superficial dorsal horn neurons. I. Modulation of A-type $\mathrm{K}^{+}$ currents. J Neurophysiol 90:1671-1679.

Huang YY, Li XC, Kandel ER (1994) cAMP contributes to mossy fiber LTP by initiating both a covalently mediated early phase and macromolecular synthesis-dependent late phase. Cell 79:69-79.

Hylden JL, Wilcox GL (1980) Intrathecal morphine in mice: a new technique. Eur J Pharmacol 67:313-316.

Ikeda H, Heinke B, Ruscheweyh R, Sandkuhler J (2003) Synaptic plasticity in spinal lamina I projection neurons that mediate hyperalgesia. Science 299:1237-1240.

Impey S, Obrietan K, Wong ST, Poser S, Yano S, Wayman G, Deloulme JC, Chan G, Storm DR (1998) Cross talk between ERK and PKA is required for $\mathrm{Ca}^{2+}$ stimulation of CREB-dependent transcription and ERK nuclear translocation. Neuron 21:869-883.

Impey S, Obrietan K, Storm DR (1999) Making new connections: role of ERK/MAP kinase signaling in neuronal plasticity. Neuron 23:11-14.

Ji RR, Baba H, Brenner GJ, Woolf CJ (1999) Nociceptive-specific activation of ERK in spinal neurons contributes to pain hypersensitivity. Nat Neurosci 2:1114-1119.

Ji RR, Befort K, Brenner GJ, Woolf CJ (2002) ERK MAP kinase activation in superficial spinal cord neurons induces prodynorphin and NK-1 upregulation and contributes to persistent inflammatory pain hypersensitivity. J Neurosci 22:478-485.

Kandel ER (1997) Genes, synapses, and long-term memory. J Cell Physiol 173:124-125

Karim F, Wang CC, Gereau IV RW (2001) Metabotropic glutamate receptor subtypes 1 and 5 are activators of extracellular signal-regulated kinase signaling required for inflammatory pain in mice. J Neurosci 21:3771-3779.

Kawasaki Y, Kohno T, Zhuang ZY, Brenner GJ, Wang H, Van Der Meer C, Befort K, Woolf CJ, Ji RR (2004) Ionotropic and metabotropic receptors, protein kinase A, protein kinase $\mathrm{C}$, and Src contribute to C-fiberinduced ERK activation and cAMP response element-binding protein phosphorylation in dorsal horn neurons, leading to central sensitization. J Neurosci 24:8310-8321.

Kim SJ, Thomas KS, Calejesan AA, Zhuo M (1998) Macromolecular synthesis contributes to nociceptive response to subcutaneous formalin injection in mice. Neuropharmacology 37:1091-1093.

Kornhauser JM, Greenberg ME (1997) A kinase to remember: dual roles for MAP kinase in long-term memory. Neuron 18:839-842.

Kurino M, Fukunaga K, Ushio Y, Miyamoto E (1995) Activation of mitogen-activated protein kinase in cultured rat hippocampal neurons by stimulation of glutamate receptors. J Neurochem 65:1282-1289.

Lever IJ, Pezet S, McMahon SB, Malcangio M (2003) The signaling components of sensory fiber transmission involved in the activation of ERK MAP kinase in the mouse dorsal horn. Mol Cell Neurosci 24:259-270. 
Levine JD, Fields HL, Basbaum AI (1993) Peptides and the primary afferent nociceptor. J Neurosci 13:2273-2286.

Li P, Zhuo M (1998) Silent glutamatergic synapses and nociception in mammalian spinal cord. Nature 393:695-698.

Li P, Zhuo M (2001) Cholinergic, noradrenergic, and serotonergic inhibition of fast synaptic transmission in spinal lumbar dorsal horn of rat. Brain Res Bull 54:639-647.

Li P, Calejesan AA, Zhuo M (1998) ATP P2x receptors and sensory synaptic transmission between primary afferent fibers and spinal dorsal horn neurons in rats. J Neurophysiol 80:3356-3360.

Li P, Kerchner GA, Sala C, Wei F, Huettner JE, Sheng M, Zhuo M (1999) AMPA receptor-PDZ interactions in facilitation of spinal sensory synapses. Nat Neurosci 2:972-977.

Lin Q, Peng YB, Willis WD (1996) Possible role of protein kinase C in the sensitization of primate spinothalamic tract neurons. J Neurosci 16:3026-3034.

Martin KC, Michael D, Rose JC, Barad M, Casadio A, Zhu H, Kandel ER (1997) MAP kinase translocates into the nucleus of the presynaptic cell and is required for long-term facilitation in Aplysia. Neuron 18:899-912.

Molander C, Xu Q, Grant G (1984) The cytoarchitectonic organization of the spinal cord in the rat. I. The lower thoracic and lumbosacral cord. J Comp Neurol 230:133-141.

Nakanishi S (1992) Molecular diversity of glutamate receptors and implications for brain function. Science 258:597-603.

Nicoll RA, Malenka RC (1995) Contrasting properties of two forms of longterm potentiation in the hippocampus. Nature 377:115-118.

Obrietan K, Impey S, Storm DR (1998) Light and circadian rhythmicity regulate MAP kinase activation in the suprachiasmatic nuclei. Nat Neurosci 1:693-700.

Orban PC, Chapman PF, Brambilla R (1999) Is the Ras-MAPK signalling pathway necessary for long-term memory formation? Trends Neurosci 22:38-44.

Otani S, Auclair N, Desce JM, Roisin MP, Crepel F (1999) Dopamine receptors and groups I and II mGluRs cooperate for long-term depression induction in rat prefrontal cortex through converging postsynaptic activation of MAP kinases. J Neurosci 19:9788-9802.

Otsuka M, Yoshioka K (1993) Neurotransmitter functions of mammalian tachykinins. Physiol Rev 73:229-308.

Randic M, Jiang MC, Cerne R (1993) Long-term potentiation and longterm depression of primary afferent neurotransmission in the rat spinal cord. J Neurosci 13:5228-5241.

Roberson ED, English JD, Adams JP, Selcher JC, Kondratick C, Sweatt JD (1999) The mitogen-activated protein kinase cascade couples PKA and PKC to cAMP response element binding protein phosphorylation in area CA1 of hippocampus. J Neurosci 19:4337-4348.
Robinson MJ, Cobb MH (1997) Mitogen-activated protein kinase pathways. Curr Opin Cell Biol 9:180-186.

Ruscheweyh R, Sandkuhler J (2002) Lamina-specific membrane and discharge properties of rat spinal dorsal horn neurones in vitro. J Physiol (Lond) 541:231-244.

Sandkuhler J, Liu X (1998) Induction of long-term potentiation at spinal synapses by noxious stimulation or nerve injury. Eur J Neurosci 10:2476-2480.

Schaefer ML, Wong ST, Wozniak DF, Muglia LM, Liauw JA, Zhuo M, Nardi A, Hartman RE, Vogt SK, Luedke CE, Storm DR, Muglia LJ (2000) Altered stress-induced anxiety in adenylyl cyclase type VIII-deficient mice. J Neurosci 20:4809-4820.

Shen KZ, North RA (1992) Substance P opens cation channels and closes potassium channels in rat locus coeruleus neurons. Neuroscience 50:345-353.

Stevens CF (1998) A million dollar question: does LTP = memory? Neuron 20:1-2.

Szallasi A, Blumberg PM (1999) Vanilloid (capsaicin) receptors and mechanisms. Pharmacol Rev 51:159-212.

Wei F, Li P, Zhuo M (1999) Loss of synaptic depression in mammalian anterior cingulate cortex after amputation. J Neurosci 19:9346-9354.

Wei F, Qiu CS, Kim SJ, Muglia L, Maas JW, Pineda VV, Xu HM, Chen ZF, Storm DR, Muglia LJ, Zhuo M (2002) Genetic elimination of behavioral sensitization in mice lacking calmodulin-stimulated adenylyl cyclases. Neuron 36:713-726.

Wong ST, Athos J, Figueroa XA, Pineda VV, Schaefer ML, Chavkin CC, Muglia LJ, Storm DR (1999) Calcium-stimulated adenylyl cyclase activity is critical for hippocampus-dependent long-term memory and late phase LTP. Neuron 23:787-798.

Woolf CJ, Thompson SW (1991) The induction and maintenance of central sensitization is dependent on $N$-methyl-D-aspartic acid receptor activation; implications for the treatment of post-injury pain hypersensitivity states. Pain 44:293-299.

Xia Z, Dudek H, Miranti CK, Greenberg ME (1996) Calcium influx via the NMDA receptor induces immediate early gene transcription by a MAP kinase/ERK-dependent mechanism. J Neurosci 16:5425-5436.

Yoshimura M, Jessell T (1990) Amino acid-mediated EPSPs at primary afferent synapses with substantia gelatinosa neurones in the rat spinal cord. J Physiol (Lond) 430:315-335.

Zhao MG, Toyoda H, Lee YS, Wu LJ, Ko SW, Zhang XH, Jia Y, Shum F, Xu H, Li BM, Kaang BK, Zhuo M (2005) Roles of NMDA NR2B subtype receptor in prefrontal long-term potentiation and contextual fear memory. Neuron 47:859-872.

Zhuo M (2004) Central plasticity in pathological pain. Novartis Found Symp 261:132-154. 